\title{
Triunfadores, desplazados sociales y Cenicientas. Representaciones sobre raza y ascenso social en la segunda mitad del siglo $\mathrm{XX}^{1}$
}

\author{
Pietro Pisano ${ }^{2}$ \\ Universidad Nacional de Colombia, Bogotá, Colombia ${ }^{3}$ \\ pierbr.pisano@gmail.com \\ Recibido: 15 de julio de 2013 \\ Aceptado: 9 de septiembre de 2013
}

Artículo de investigación basado en los resultados del proyecto "Escapando a la desdicha genealógica. El surgimiento y participación de las clases medias 'negras' en la vida nacional colombiana". Financiado por Colciencias (código 1101-521-28382) y dirigido por la profesora Mara Viveros Vigoya. Fue realizado entre los años 2011 y 2013.

2 Historiador egresado de la Università degli Studi di Trieste (Italia). Magíster en Historia de la Universidad Nacional de Colombia.

3 Investigador del Grupo Interdisciplinario de Estudio de Género - GIEG, de la misma Universidad. 


\title{
Triunfadores, desplazados sociales y Cenicientas. Representaciones sobre raza y ascenso social en la segunda mitad del siglo XX
}

\section{Resumen}

A partir del estudio de artículos publicados en revistas colombianas (en particular la revista Cromos) en la segunda mitad del siglo XX, este artículo se propone analizar algunas representaciones que se produjeron acerca del ascenso social de personas negras. Se toman en consideración las historias de algunos personajes en distintos momentos: el juez José Antonio Camacho, el boxeador Kid Pambelé, la modelo Laura Mosquera y la pianista Teresa Gómez. Aunque emergieron en contextos profesionales diferentes, las narrativas sobre sus trayectorias tienen en común el enfatizar cómo las representaciones de clase articuladas con aquellas de razay de género fueron utilizadas para mostrar la dificultad, para una persona negra, de insertarse en un contexto social diferente a los sectores populares, mostrando tanto su supuesta incompatibilidad con los valores de la clase media como la imposibilidad de integrarse plenamente en una sociedad dominada por los blancos.

Palabras claves: Movilidad social, Racismo, Discriminación, Prejuicios raciales, Clasismo.

Palabras clave descriptores: Racismo, Discriminación racial, Prejuicios y antipatías, Movilidad social, Siglo XX.

\section{Winners, Socially Displaced and Cinderellas: Representations of Race and Social Climbing in the Second Half of the Twentieth Century}

\begin{abstract}
From the study of articles published in Colombian magazines (particularly Cromos magazine) in the second half of the twentieth century, this article proposes the analysis of some representations about upward mobility of black people. Consideration is given to the stories of some characters at different times: the judge Jose Antonio Camacho, the boxer Kid Pambele, the model Laura Mosquera and the pianist Teresa Gómez. Although they emerged in different professional contexts, narratives about their paths have in common the emphasis on how the class representations articulated with the race and gender ones and were used to show the difficulty for a black person to be inserted in a social context different from the popular sectors, showing both their alleged incompatibility with the values of the middle class as well as the inability to fully integrate into a society dominated by whites. Keywords: Social Mobility, Racism, Discrimination, Racial Prejudice, Classism.
\end{abstract}

Key words plus: Racism, Race discrimination, Prejudices And Antipathies, Social Mobility, 20th Century.

\section{Triunfantes, deslocados sociais e Cinderelas Representações sobre raça e promoção social na segunda metade do século XX}

\section{Resumo}

A partir do estudo de artigos publicados em revistas colombianas (em particular a revista Cromos) na segunda metade do século XX, este artigo propõe-se analisar algumas representações produzidas acerca da promoção social de pessoas negras. Levaram-se em conta as histórias de alguns personagens em diferentes momentos: o juiz José Antonio Camacho, o pugilista Kid Pambelé, a modelo Laura Mosquera e a pianista Teresa Gómez. Embora emergissem em contextos profissionais diferentes, as narrativas sobre as suas trajetórias têm em comum a ênfase sobre como as representações de classe articuladas com aquelas de raça e gênero, foram utilizadas para mostrar a dificuldade, para uma pessoa negra, de se inserir em um contexto social diferente aos setores populares, mostrando tanto sua suposta incompatibilidade com os valores da classe média como a impossibilidade de se integrar plenamente em uma sociedade dominada por brancos.

Palavras-chaves: Promoção social, Racismo, Discriminação, Prejuízos raciais, Classismo.

Palavras-chave descritores: Racismo, Discriminação racial, Preconceitos e antipatias, Mobilidade social, Século XX. 


\section{Introducción}

La intersección entre raza y clase ha representado históricamente una de las peculiaridades de la sociedad colombiana, en la cual el orden de clases se ha superpuesto de manera compleja a la jerarquía racial de la Nación, al identificar al negro con la pobreza y la subordinación y al blanco con la riqueza y el gobierno. Como lo advierte el antropólogo Peter Wade (1997), esta división no es exactamente dicotómica, dado que existen personas blancas pobres y personas negras de clase media. En efecto, el imaginario que relacionaba el ser negro con la pobreza, chocaba con la existencia de personas de ese grupo que habian ascendido socialmente, distinguiéndose en varios ámbitos de la vida del país. Las historias aquí analizadas tienen por protagonistas a algunos hombres y mujeres racializados y racializadas como negros y negras que, entre las décadas de 1940 y 1990, protagonizaron procesos de ascenso social. Se mira al detalle la representación que se dio de esos procesos en la revista Cromos.

Para el argumento que interesa a este artículo, Cromos representa una fuente documental interesante. Su publicación constante desde 1916 permite analizar los cambios ocurridos en la sociedad colombiana a lo largo del siglo XX y la interpretación que tuvieron en una revista dirigida a un público amplio, conformado tanto por hombres como por mujeres. En términos de clase, los datos que lectoras y lectores proporcionaban en las cartas que escribian a las diferentes secciones de la revista permiten plantear que se trataba principalmente de personas de los sectores medios de la sociedad.

Un dato interesante es el relacionado con los colores de piel que lectoras y lectores se atribuian en sus cartas a secciones como la de belleza, entre las décadas de 1940 y 1950 y de búsqueda de pareja entre finales de la década de 1960 e inicio de la década de 1970: se trataba de personas que se definían a sí mismas generalmente como trigueñas, en menor medida morenas y más raramente blancas y negras. Es decir, un público que se identificaba mayoritariamente en categorías diferentes al blanco que al mismo tiempo, era presentado como modelo ideal, emblema del poder, la riqueza, la modernidad y la civilización.

En lo que tiene que ver con las relaciones raciales y, en particular, con la población negra, en Cromos se puede observar el pasaje desde la invisibilidad, es decir su ausencia como sujeto específico de la sociedad (Friedemann, 1983), a un progresivo reconocimiento 
de sus especificidades culturales que con el tiempo, como efecto del trabajo del movimiento negro, llegó a incluir la discriminación racial como problema que la afectaba (Viveros et al., 2013). Lo mismo ocurre con las relaciones de género. Sin embargo, tanto la mujer como el hombre modernos, con las diferentes acepciones que se asignaron a estos términos en el tiempo, siguieron teniendo una precisa connotación de raza y de clase, siendo representados y representadas por personas blancas de clase media o alta. La prensa se confirma así como una fuente importante para analizar el discurso producido por una elite, así como los imaginarios y los estereotipos que esta reproduce sobre las minorias (Van Dijk, 2010).

El análisis de las historias que se tratan a continuación se lleva a cabo teniendo en cuenta dos referentes teóricos. Primero, el Análisis critico del discurso, a través del cual se pretende evidenciar las relaciones estructurales de dominación, discriminación, poder y control que se manifiestan en el lenguaje (Blommaert y Bulchaen, 2000). El segundo referente teórico es la interseccionalidad. Muchos de los documentos analizados en efecto, muestran que la raza y la clase no solamente se articulan y se influencian entre ellas sino que, para comprender cómo operan es necesario tener en cuenta otras categorias, principalmente el género y la sexualidad (Viveros, 2008) ${ }^{4}$. Siguiendo la propuesta de la teórica afroestadounidense Kimberlé Williams (1991), se tendrán en cuenta las múltiples dimensiones de la experiencia (o en este caso, de la representación de la experiencia) de hombres y mujeres negras, mostrando la interdependencia de estas categorias.

\section{Un Santo Domingo no puede ser moreno: raza, género y clase en Colombia}

Sentado en la sala VIP del aeropuerto de Rionegro está el nieto del industrial Julio Mario Santo Domingo. Lo primero que desconcierta a todos aquellos que lo miran es que sea moreno, feo y, además, amanerado. Pero nadie lo expresa en voz alta. Al fin y al cabo, podría ser quien asuma la presidencia del Grupo Bavaria en unos años (Samper, 2000).

Este fragmento, extraído de un artículo publicado en la revista Cromos en el año 2000, describe de manera eficaz los imaginarios que se han

\footnotetext{
4 Para un análisis exhaustivo sobre la interseccionalidad y su uso como herramienta metodológica ver McCall (2005) y Viveros (2008).
} 
construido históricamente en Colombia acerca de la clase, mostrando su articulación con la raza y el género. Como ha observado Viveros (2007, p. 107), desde la Independencia la construcción de la Nación asignó un lugar subordinado a aquellos grupos "que no se adecuaban a las características del varón 'blanco', propietario, heterosexual", es decir, las minorias étnico-raciales, las mujeres, los sectores populares y las minorias sexuales. El desconcierto que el periodista atribuye a los pasajeros de la sala VIP muestra que, según la expectativa de esas personas, un miembro de la elite del país debería ser blanco, bello y heterosexual. Por su color de piel, fealdad y amaneramiento (relacionado con la homosexualidad), el hombre que tenían delante de sí hubiera encajado más con los sectores marginados de la sociedad ${ }^{5}$.

Al querer subrayar la inmutabilidad de esos estereotipos y de las jerarquías sobre las cuales se construyó la Nación, el autor del artículo aclaró casi inmediatamente que se trataba de un impostor, más exactamente, como ya se le definía en el título, "el más grande impostor": un hombre de origen popular, oriundo de la costa atlántica y homosexual, arrestado en esos días por falsificación de identidad.

El fragmento citado subraya también otro aspecto. Los pasajeros de la sala VIP, en efecto, deciden ocultar el desconcierto que les atribuye el periodista, como si consideraran improbable, pero no imposible, que una persona no-blanca pudiera ocupar una posición social privilegiada. De hecho, a finales del siglo XX se conocian y habian adquirido cierta visibilidad mediática, casos de personas negras que se distinguían en varios ámbitos de la sociedad: políticos, artistas, deportistas e intelectuales (Viveros et al., 2013), así como directivos de empresas públicas y privadas (Urrea, 2011). De alli su silencio, pero también la sospecha sobre ese miembro anómalo de la familia Santo Domingo.

La mencionada sospecha poco tiene que ver con su verdadera identidad (los pasajeros no están enterados de ella) sino expresa un fenómeno más amplio, experimentado por personas negras que ocupan posiciones de clase interpretadas como discordantes con su fenotipo. En su estudio sobre personas negras de clase media en Bogotá, Gil evidencia la cotidianidad de la sospecha con la cual tienen que lidiar, debido a la idea de que "si una persona negra está en ciertos espacios es para cometer algún delito" (Gil, 2010, p. 145). La expectativa hacia

5 La articulación entre raza y clase será desarrollada a lo largo del artículo. En cuanto a lo que tiene que ver con la sexualidad, se recomiendan los estudios de Bustamante (2008, p. 145) y Pisano (2009), que observaron cómo los homosexuales afeminados, indicados generalmente con el despectivo de locas, estaban asociados en el imaginario con un bajo rango social y con lugares proclives al delito. 
una persona de este grupo étnico-racial es que se trate necesariamente de alguien de escasos recursos económicos, que no pueda acceder a ciertos bienes de consumo y que ocupa un rango subordinado en el mercado laboral.

Un fenómeno parecido fue observado por Figueiredo (1990) en el caso brasileño. Así, no es difícil plantear que, aún cuando se hubiese tratado de un miembro de la familia Santo Domingo, el protagonista del artículo tendría que lidiar con esa actitud y que por el contrario, un impostor que correspondiera a las características esperadas de una persona de esa posición social, no generaria dudas sobre su identidad.

Como en otros países de América Latina, también en Colombia las jerarquizaciones de clase se articulan con jerarquizaciones raciales que relacionan los blancos con la riqueza, el poder, la civilización, la urbanidad, la educación y la cultura, y la gente negra con la pobreza, la ignorancia, la rusticidad (Wade, 1997, p. 52). Las representaciones de clase se cruzan con aquellas de raza, pero también de género. Un ejemplo es la construcción de la identidad de clase media que se desarrolló en Colombia en la década de 1950. De acuerdo con López Pedreros (2009), ella se construyó alrededor de los conceptos de verdaderos hombres y verdaderas mujeres, usados para definir a los empleados y a las empleadas: los primeros se caracterizarian, entre otras cosas, por desempeñarse en trabajos mentales e intelectuales, poseer moralidad, ser padres y maridos responsables que apoyaban y mantenían a sus familias; las segundas por ser madres, esposas, trabajadoras por elección (y bajo el permiso del esposo) y no por obligación, ángeles del hogar o de la oficina.

Dicha construcción identitaria se realizó en contraposición con aquella de las mujeres y los hombres de la clase obrera, considerados los unos como perezosos, irresponsables, pasivos, subordinados, débiles, dependientes y violentos y las otras como provistas de ciertas características masculinas como la insubordinación, la agresividad y la fuerza muscular, además de la necesidad de trabajar (López Pedreros, 2009). Estas representaciones de género y de clase pueden ser interpretadas también en clave racial: los estereotipos sobre las y los obreros repiten en buena medida aquellos sobre los hombres y las mujeres negras. Eso es evidente si se consideran las representaciones de raza y de género producidas desde los años cincuenta sobre las y los habitantes del Palenque de San Basilio, que en esa época se volvieron el emblema, en sentido peyorativo, de lo que significaría ser negro. Varios artículos perpetuaron el estereotipo de los hombres negros alcohólicos y perezosos, enfatizando la inversión 
de los roles de género que se verificaría en esa comunidad, donde los hombres asumirian las labores domésticas, dejando a sus esposas el rol de proveedoras (Pisano, 2012b).

Aunque en mi opinión, no se puede hablar de hombres necesariamente feminizados o de mujeres necesariamente masculinizadas, las y los palenqueros (y, por extensión, todas las personas negras, tal como eran imaginadas por quienes hablaban de ellas) representarian una anomalía respecto a una norma que, desde la época colonial, ha sido representada por lo blanco (Hering, 2011), entendiendo con ese término no solamente el fenotipo sino también las representaciones de clase y de los roles de género que éste conlleva. La articulación de los prejuicios raciales, de clase y de género llevó a considerar a las personas negras incompatibles con los sectores medios y altos de la sociedad. En los casos analizados a continuación, ese imaginario llevó a las y los periodistas de Cromos a justificar su presencia en un lugar social diferente al que deberían ocupar según los imaginarios asociados con la gente negra. De la misma manera, estos imaginarios entran constantemente en juego para explicar los límites de su inserción social y sus fracasos en el intento de alcanzarla.

\section{El derrotado y el triunfador: Chivas y Antonio José Camacho}

Entre 1942 y 1943 las revistas Cromos y El Sábado publicaron dos historias que tenian por protagonistas a dos hombres negros, con resultados diferentes en su proyecto de ascenso social. La primera era la de Chivas. Desde el inicio, el periodista enfatizó el fracaso con que se había concluido su intento: "En la vida de este derrotado -afirmó- todo ha sido negro. Su destino, su pasado, su presente, su porvenir" (Abello, 1942). Nacido en el Chocó, hacía dos años había llegado a Bogotá en busca "de nuevos horizontes". Rechazado en todos los puestos de trabajo en que se había postulado, fuera por "incapacidad" o por su "ingenuidad de provinciano" que le había impedido entender las dinámicas de la sociedad capitalina (en la cual, entre otras, de nada servirian las cartas de recomendación "que en provincia tienen tan alto valor").

Además de pasar por estas vicisitudes, la derrota de Chivas sería originada también por la frustración de su supuesto deseo de acceder al amor de una mujer blanca. Parte de su deseo de ascenso fue explicado con base en eso; incluso su intento de entrar en el ejército, 
de donde fue expulsado, estaria relacionado a la posibilidad que eso le daría de poder conquistar a una mujer blanca. Fracasados estos intentos, Chivas terminaría por volverse habitante de la calle.

La historia de Antonio José Camacho es contraria a la de Chivas. Hijo de un albañil y de una mujer "rubia", había nacido en una familia pobre en Cali. Huérfano de padre, había podido cursar sus estudios en su ciudad de origen gracias a una beca departamental, y posteriormente en Bogotá, en medio de muchas privaciones pero con la ayuda de algunas personas blancas, se graduó en Derecho de la Universidad Libre y terminó por convertirse en juez. Casado con una mujer blanca y pudiente, vivía con ella en una casa elegante, decorada "a la moda bogotana".

Desde el punto de vista de los periodistas que narraron estas historias, las trayectorias de Chivas y de Camacho hacen del uno un derrotado y del otro un triunfador, enfatizando la marginación a la cual estaría condenado el primero y la inserción en la sociedad que alcanzaría el segundo. Entender las diferencias entre las representaciones de estos dos hombres negros remite, en mi opinión, a la ideología del mestizaje que dominaba en Colombia en esa época ${ }^{6}$ y a la importancia que se atribuía a la mezcla, fisica y cultural, para el ascenso social de una persona negra.

En su estudio sobre las relaciones raciales en Colombia, Wade (1997) ha mostrado cómo en un contexto discriminatorio como el de la Colombia mestiza, las personas negras que ascienden socialmente pueden ser aceptadas individualmente por medio de su adaptación cultural (es decir, adhiriendo a los valores dominantes), del matrimonio con una persona de piel más clara y al pacto de que eso no implique la aceptación

6 El mestizaje es un fenómeno complejo que, como ideología nacionalista, ha sido interpretado en diferentes formas al punto que, observa Wade (2003, p. 277), se puede pensar en múltiples mestizajes, que pueden coexistir en la misma época. En algunos casos puede expresarse en medidas de blanqueamiento físico y/o cultural de la Nación (Friedemann, 1992; Wade, 1997; Rojas, 2001; Pisano, 2012a) y en la negación de las identidades y problemáticas específicas de las minorias étnico-raciales, homologadas dentro de un concepto genérico de ciudadania (Friedemann, 1983; 1992); en otros, puede llevar a un reconocimiento de la contribución de dichas minorias, así como a su relativa aceptación, particularmente en el ámbito cultural o en los relatos sobre vivencias cotidianas y personales (Wade, 2003). La década de 1940 reflejó dicha complejidad. Por un lado, el proyecto de blanqueamiento de la población fue llevado a cabo, por ejemplo, a través de actos dirigidos al favorecimiento de la migración europea a Colombia, cuyo objetivo era borrar la influencia considerada negativa, de la gente negra e indígena; por el otro, el mestizaje fue exaltado en la representación de Colombia como un país surgido del encuentro entre los españoles y los indígenas de la época de la conquista (no los del presente). Sin embargo, esta interpretación del mestizaje excluía a la población negra, por no ser considerada heredera de una cultura propia (Pisano, 2012a). 
de todo el grupo 7 . La derrota de Chivas y el triunfo de Camacho pueden ser explicados con base en este mecanismo. El fracaso del primero sería la consecuencia de su imposibilidad de participar tanto del mestizaje fisico hacia arriba, es decir, hacia lo blanco, como del cultural, quedando atado, según la definición del periodista, a un destino negro, que en la mentalidad de la época significaba marginación, subordinación y alejamiento del proyecto nacional.

Por el contrario, Camacho representaría la encarnación misma de los diferentes significados atribuidos al mestizaje. En su caso, el mestizaje coincide con el blanqueamiento. Prueba de ello serian sus estudios, la posición social conquistada, su matrimonio y su lejanía de reivindicaciones raciales como hombre negro, siendo más bien, en las palabras de Osorio, "la fuerza creadora del Niger" que se fundia en "nuestro conglomerado híbrido" (1943) ${ }^{8}$. La fusión, sin embargo, no implica la igualdad de los distintos elementos que se unen; más bien, tal como la describe Osorio, revela la predominancia del elemento considerado superior, el blanco, y la importancia de que, por medio de las dinámicas mencionadas, una persona negra se acerque a ello para lograr insertarse en la sociedad. De hecho, si el pasado, el presente y el porvenir de Chivas están marcados por el negro, los del juez están marcados por el blanco.

A este propósito, es significativa la descripción del lugar en que se tiene el encuentro entre el periodista y Camacho: el estudio de su casa, decorada al estilo bogotano -asociado a la blancura en la jerarquía de la Nación-, en la cual, "en el puesto de honor" estaba un retrato de tamaño natural de su madre. La parte negra de la historia del juez es invisibilizada, lo que es coherente con la imagen triunfadora que el periodista quería dar de él y también con los relatos sobre la historia nacional, en que la contribución de la gente negra fue ocultada (Friedemann, 1983, 1992; Pisano, 2012a). La coherencia de Camacho con el proyecto nacional fue representada incluso en su apariencia:

7 Considero importante subrayar que ascenso social y adaptación cultural no están necesariamente relacionadas entre si. Estudios como el de Figueiredo (1990), Viveros y Gil (2010) y Viveros et al. (2013) han mostrado que, en algunos casos, el ascenso social a través de la escolarización puede llevar al fenómeno opuesto, es decir, al desarrollo de una identidad étnico-racial, entendida como un sentimiento de pertenencia a un pasado común.

8 La historia de Camacho apareció en un momento particular en la historia de las relaciones raciales en Colombia, que puede contribuir a explicar la lejanía de Camacho de reivindicaciones raciales. En junio de 1943, unos meses antes de la publicación del artículo, había sido organizada la primera manifestación de la gente negra en el país: el Día del Negro, y fundado el primer movimiento negro: el Club Negro de Colombia. A pesar de tratarse de una manifestación y de un movimiento muy pequeños, por el escaso número de personas involucradas, tuvieron mucho espacio en la prensa colombiana, que las acusó de querer llevar a Colombia un problema supuestamente desconocido: el de las tensiones raciales (Zapata, 1990; Pisano, 2012a). 
Osorio lo describe como un hombre cuyo pigmento se estaba "opacando" y cuyo cabello, "cortado al rape", "trata[ba]" de nevar", es decir, se estaba volviendo blanco.

La narración de Osorio muestra otro elemento: blanquearse no significa volverse blanco sino solamente acercársele. Un fragmento del artículo es muy útil para explicar este concepto. A partir de la historia de Camacho y de la observación del ambiente que lo rodeaba, al final del artículo Osorio reflexiona de esta manera:

Oyendo aquello, pensé una vez más que en este trópico la levadura africana, que se va diluyendo una vez más en el ambiente, y que enmascarada de blancura va ascendiendo hacia las esferas aristocráticas y oligárquicas, es una de las más equilibrantes energías de nuestra nacionalidad (Osorio, 1943).

En la opinión del periodista, el triunfo de Camacho, es decir, su ascenso hacia una posición social privilegiada, sería posible gracias a la atenuación (dilución) de su origen africano y a la adquisición de una máscara de blancura que lo acerca a los sectores dominantes. Sin embargo, ni la dilución ni la máscara cancelan totalmente el hecho de que se trate de un hombre negro: desde el título mismo del artículo él es el "Negro Camacho", y con ese adjetivo se acompaña continuamente su figura a lo largo del texto.

Los relatos sobre Chivas y Camacho permiten plantear algunas reflexiones sobre las representaciones del ascenso social de hombres negros a mediados del siglo XX. La derrota del uno y el triunfo del otro están relacionados con cuestiones muy parecidas: la posibilidad de lograr un capital cultural a través de la educación formal, una posición laboral prestigiosa y la adquisición de los valores que estaban en la base de la sociedad mestiza. Uno de estos valores es justamente la mezcla racial hacia arriba en la jerarquía racial de la Nación (Wade, 1997), expresada en la importancia atribuida en las dos historias a la posibilidad de acceder a mujeres blancas. Este aspecto tuvo gran importancia en muchos artículos sobre hombres negros exitosos publicados en la revista Cromos en la segunda mitad del siglo XX: además de sus logros en los ámbitos laborales en que se desempeñaban, frecuentemente sus retratos (así como el material fotográfico que los acompañaba) enfatizaron su capacidad de conquistar a mujeres del grupo que, velada o explícitamente, era considerado superior. De manera parecida a lo que algunos estudios han mostrado para el caso 
de Martinica (Fanon, 1952) y Brasil (Azevedo, 1953; Moutinho, 2004), también en Colombia las relaciones interraciales entre hombres negros y mujeres blancas fueron interpretadas como muestra de la posición social conquistada.

El triunfo o la derrota representados por Camacho y Chivas están relacionados con su posibilidad o imposibilidad de adquirir, a través de los recursos descritos anteriormente, la máscara de blancura. Aunque no se vuelva blanco, el primero puede beneficiarse, según la lectura que dio el narrador de su historia, de los privilegios que el grupo dominante podía otorgar a quienes adherian a sus valores; por el contrario, el segundo, quedaría atado a un "pasado, un presente y un porvenir negros", es decir, de pobreza y marginación, justamente por la imposibilidad de acceder a ellos, confirmando así el orden socioracial de la Nación.

\section{Un desplazado social: Kid Pambelé}

Pambelé (...) fue siempre un desplazado social, un muchacho pobre que saltó de Chambacú a otro barrio de chozas, en Caracas, y de allí saltó repentinamente a la gloria (...). El problema de Pambelé es que no puede dominar la situación de ídolo en que se encuentra en este momento, pero tampoco puede volver a su estado anterior. (Gossain, 1974)

Con esta frase, un periodista describió en 1974 la condición peculiar en que se encontraría el campeón de boxeo Kid Pambelé, dividido entre un lugar de ídolo al cual no lograría adaptarse y la condición original de la cual había salido debido a sus éxitos deportivos. En términos de clase, esto se podría resumir en una tensión entre el nuevo lugar social ocupado y el de origen (relacionado, como veremos, a su pertenencia étnico-racial) que, aunque perdido, seguiría ejerciendo influencia sobre quienes ascendian socialmente.

Nacido en San Basilio de Palenque pero criado en Cartagena, a donde había migrado su familia debido a sus precarias condiciones económicas, Pambelé emergió como deportista a inicio de la década de 1970, cuando ganó el título mundial de boxeo. A raíz de esto, la prensa le dedicó numerosos artículos, en muchos de los cuales emerge la tensión entre las y los periodistas que narraban su historia, a menudo relacionándolo 
con el estereotipo de hombre negro (expresado, por ejemplo, en el énfasis dado a su origen palenquero) de sectores populares y los intentos del boxeador por alejarse de ellos.

Además que a sus habilidades de deportista y a sus éxitos, frecuentemente esos artículos dedicaron espacio a la vida privada del campeón, enfocándose en aspectos como su relación con el dinero, su conducta sexual y sus vicios. En lo que tiene que ver con el dinero, varios artículos subrayaron la extravagancia de sus gastos, como por ejemplo un anillo de oro del valor de 3500 pesos de la época que compraria tras haberlo mirado ávidamente en una vitrina (Holguín, 1973), o un diente de oro, "simbolo de poder y bonanza" que según un artículo, se pondría gracias a los 5000 dólares ganados en un encuentro. El mismo artículo enfatizó otro aspecto, es decir, la inversión de su dinero para acceder a comodidades básicas que hasta entonces no tenía: un colchón, una nevera, una estufa eléctrica y un juego de muebles para la sala, gastos que demostrarian que Pambelé seguía siendo "un muchacho de Palenque" (Gossaín, 1973, 26 de febrero).

Las referencias a su origen palenquero o, en otros casos, al barrio de Chambacú donde vivió en Cartagena, fueron frecuentes en las notas periodísticas que se escribieron sobre él. Ambas tienen una connotación implícita de raza y de clase al ser lugares habitados por personas negras de escasos recursos económicos: en el caso específico, parecían querer recordar que el personaje del que estaban hablando era un hombre negro y pobre que, aunque tuviera fama y dinero, no dejaba de tener actitudes que delataban su origen. De allí también la insistencia igualmente frecuente, sobre todo en la década de 1970, sobre su hablado vulgar y su ignorancia: en una ocasión, Pambelé afirmaría no saber quiénes eran "García Vaquez" (el escritor Gabriel García Márquez) o "Nison" (Richard Nixon, entonces presidente de los Estados Unidos) (Gossaín, 1972).

Así como era representado el Palenque de San Basilio, también su hijo Pambelé estaría alejado de la modernidad y del mundo contemporáneo, a los cuales intentaría acercarse a través del acceso a las comodidades de las que se habló o adoptando una pinta cónsona a su estatus de clase (en otras ocasiones, la prensa insistió, por ejemplo, en su pasión por la moda italiana). Sin embargo, la extravagancia de algunos gastos, así como su manera de hablar y su supuesto desconocimiento del mundo contemporáneo fueron utilizados para demostrar su dificultad para entrar a pleno título en su nueva condición. Un fenómeno parecido se puede observar en los relatos sobre su vida 
sexual. Adhiriendo al estereotipo construido sobre los hombres palenqueros (y más en general, sobre los hombres negros), muchos artículos lo describieron como un hombre descontrolado en la esfera sexual, marido infiel y dedicado al alcohol y a las drogas ${ }^{9}$.

Como mencioné anteriormente, en algunos casos los artículos de Cromos dieron espacio a declaraciones en las cuales Pambelé intentó alejarse de ese estereotipo. En uno de ellos, al diferenciarse de otros campeones (que en muchos casos eran hombres negros), se presentó como padre y marido responsable, un administrador atento de su patrimonio, a través del cual quería garantizar un futuro a sus hijos. Es significativo el hecho de que estas declaraciones fueron precedidas por una frase del periodista, según la cual en esa ocasión Pambelé había hablado "con una lógica y prudencia poco frecuentes en personas de su condición cultural" (Castaño, 1975). Cabe subrayar que el artículo nunca define cuál era esta condición cultural, pero con base en lo que se planteó, considero que representa una ulterior referencia al origen social y racial del boxeador, que en este caso fue mostrado como una excepción respecto a un modelo -el de los hombres negros y pobresque en general, estaría marcado por las características de las cuales Pambelé quería alejarse.

La imagen del desplazado social remite a una inserción incompleta de quienes viven procesos de ascenso. Por su capital económico, Pambelé podía ser insertado en los sectores acomodados de la sociedad; sin embargo, los imaginarios sobre sus lugares de procedencia, geográfico, racial y social, y la influencia que seguirian ejerciendo sobre él, le impedirian apoderarse totalmente de los códigos y de los estilos de vida relacionados con su nueva posición. Consecuencia de esto sería la huída de ella, relatada por ejemplo, en un perfil psicológico publicado en 1974, que lo describió como un hombre que huía de la fama y se sentía más a gusto en compañía de obreros y empleadas domésticas (Gossaín, 1974), es decir, con personas más cercanas a su ambiente originario.

La definición de desplazado social aplicada al caso de Pambelé podría ser empleada también para referirse a otros campeones del deporte cuyas representaciones siguieron esquemas parecidos. En la misma época, otro boxeador exitoso, Bernardo Caraballo, manifestó

9 Las infidelidades, verdaderas o supuestas, de Pambelé fueron evidenciadas en dos entrevistas que la revista hizo a su esposa, quien las soportaría en cuanto era "un hombre normal y corriente", que se portaba como todos los demás. Ver Ricci (1977) y Gossaín (1973, 26 de marzo). 
una actitud parecida, al declarar que prefería vivir en su barrio de origen aún pudiendo acceder a lugares más exclusivos:

Porque estoy seguro que aquí me quieren de verdad y nadie me despreciará, aún cuando pierda el título [...] Me quedo con mi gente y no voy a tener problemas. (Cromos, 1976)

Años después, la misma declaración fue atribuida al boxeador Harold Gray, acompañada por la afirmación de un periodista según la cual, de esta manera, "no traicionó a sus ancestros, ni su condición, ni su clase, ni su raza" (Baldovi, 1994). Como veremos también en el apartado siguiente, muchos de los relatos sobre ascenso social de personas negras están caracterizados por enfatizar en una inevitabilidad que derivaría de su origen. Más que la posición y las actitudes de las y los protagonistas de esos procesos, dicha inevitabilidad expresa la expectativa que tienen hacia ellos los que narran sus historias. Así las cosas, la traición a la que alude la frase anterior puede relacionarse con la naturalización de las desigualdades sociales que, en una sociedad de clases, usa también las diferencias de sexo y, en este caso, de raza para justificarse (Viveros, 2008, pp. 172-173). Si se considera natural que una persona negra sea pobre, lo seria también el hecho de que, independientemente de su capital económico, esté más a gusto en un lugar acorde a su posición de clase y de raza. Cambiar esta situación sería una traición.

La inevitabilidad, es decir, la naturalización de esta condición, explica también el énfasis puesto en los procesos de descendientes de los campeones negros que seguirian a la época del éxito deportivo y económico. La tensión entre el viejo mundo y el nuevo mundo manifestada en la imagen del desplazado social parece solucionarse en esos relatos, con el retorno de estas personas a su estado originario. Una vez más, el caso de Pambelé es emblemático. Desde lla década de 1980 los artículos que le fueron dedicados en la revista enfatizaron su parábola descendiente: debido a su adicción al alcohol y a las drogas, el antiguo campeón perdería todo, encontrándose ahora arruinado y pobre (Araújo, 1991) ${ }^{10}$.

10 Un análisis detallado de los relatos sobre las trayectorias descendientes de los deportistas negros escapa los objetivos de este artículo. Sin embargo, considero importante subrayar que merecería ser matizada. En efecto, aunque muchos artículos publicados en Cromos entre las décadas de 1970 y 1990 insistieron en la ruina económica que seguiria a la época de éxito, proporcionaron también elementos que mostraban que dicha condición era, en realidad, relativa. En efecto, muchos de ellos declararon tener propiedades y/o actividades económicas que les garantizaban rentas, vivir en casas de su propiedad, etc. Estos datos permiten plantear que, contrariamente 
En 1994 un periodista propuso una distinción entre Antonio (el verdadero nombre de Pambelé) y Kid: Antonio representaria su parte miserable, anterior y posterior al éxito, caracterizada por la pobreza; Kid sería su parte exitosa, el campeón mundial de boxeo, justamente aquella que, retomando la definición que da el título a este apartado, no había podido dominar, traicionando así, como afirmaba el subtítulo del mismo artículo, a su familia, a su pueblo y a sí mismo (González, 1994). Si, como hemos mencionado anteriormente, los rasgos distintivos del verdadero hombre-blanco, de clase media o de la elite- eran, entre otros, su capacidad de control de sí mismo y la administración atenta de su patrimonio, el énfasis en la ruina de Pambelé y en sus supuestas razones volvian a acercarlos al modelo opuesto, caracterizado por aspectos raciales y de clase. Es decir que el negro y el pobre prevalecerian en su historia al punto de determinar su decaimiento y la pérdida de su posición social.

\section{Cenicientas sin final feliz: Laura Mosquera y Teresa Gómez}

Los relatos sobre ascenso social de mujeres negras publicados en Cromos fueron menos numerosos que aquellos sobre hombres negros. Si en el caso de los hombres prevalecieron los de deportistas y, en menor medida, de intelectuales y políticos, en el caso de las mujeres las actividades prevalentes fueron aquellas relacionadas con el folclor y el modelaje. Además, contrariamente a los hombres, las mujeres negras cuya historia fue contada en Cromos, en muchos casos no procedian de sectores populares sino, más bien, de la clase media (Viveros et al., 2013). Las historias de la modelo Laura Mosquera y de la pianista Teresa Gómez analizadas en este apartado presentan aspectos insólitos respecto a las trayectoria de otras mujeres negras exitosas, compartiendo con las que se analizaron anteriormente el énfasis en su pobreza originaria, de la cual saldrian al destacarse en sus respectivos ámbitos laborales. Esta trayectoria haría de ellas las protagonistas de un cuento de hadas.

Laura Mosquera recibió el apodo de Cenicienta negra en un artículo que Cromos le dedicó en 1974. Su historia fue presentada como "un canto a la superación de la mujer de color en nuestro país":

a la miseria enfatizada en los artículos, muchos de los antiguos campeones se encontrarian en una condición relativamente estable, más comparable con una clase media que con la pobreza (Viveros et al., 2013). 
Cuando Laura Mosquera vino al mundo, nada parecía señalar que fuera una negrita diferente a todas las de su pueblo: flaca, 1lorona, con el cabello que parecía una esponjilla bon-bril coronándole lo alto de la cabeza, de ojos grandes y saltones y cuerpo pequeñísimo. No se diferenciaba en absoluto de los centenares de chiquillas como ella, que nacian todos los días entre la miseria y el calor de Istmina. (Holguín y Pabón, 1974)

Al nacer, Laura Mosquera estaría entonces en una condición parecida a la de muchas mujeres de su origen regional, racial y social. Descendiente de esclavos -como subrayó el artículo, indicaba su apellido- e hija de una familia pobre, pudo terminar la primaria gracias a la ayuda de unos familiares "asombrosamente bondadosos". Posteriormente se mudó a Bogotá, donde conseguiría un "empleo decente", terminaría el bachillerato e intentaria, inútilmente, modelar. Se fue entonces a vivir a Venezuela y alli, "descubierta en la calle" por un fotógrafo, llegaria a ser la modelo más cotizada de ese país, que podía ganar hasta 7000 dólares por mes. Un factor determinante de su éxito, según los autores de ese artículo, sería el hecho de distanciarse de sus características originarias, es decir, de mujer chocoana, negra y pobre. Ella, afirmó el autor, era diferente a las mujeres de su región:

Laura -afirman- tenía algo con que no contaban las mujeres de su tierra: la rebeldía innata, tal vez heredada de algún antepasado 'Cimarrón', el no resignarse a la miseria ni a la pobreza y un sentido de la dignidad que la hizo diferente del resto. (Holguín y Pabón, 1974)

Tal como aparecen en este fragmento, las mujeres chocoanas serian sumisas, resignadas y sin dignidad. Este estereotipo mezclaba factores raciales (al tratarse de mujeres negras), de clase (por ser pobres) y de género, al ser indicadas implícitamente como diferentes a otras mujeres, tal vez aquellas del interior, lugar desde el cual escribían los autores del artículo. La articulación de los estereotipos mencionados llevaría consecuentemente a la marginación de quienes los poseían. Por el contrario, alejarse de ellos, como haría Laura -metafórica y fisicamente- le permitirian alcanzar el éxito.

La historia de Teresa Gómez presenta elementos parecidos: hija de una mujer de Buenaventura que murió cuando ella tenía pocos dias, fue adoptada por los porteros del palacio de Bellas Artes de Medellín, una pareja blanca. Allí comenzó a tocar el piano, completó sus estudios en el Conservatorio de Música de la Universidad Nacional, volviéndose 
"la única pianista negra del país" y entrando así en un campo, el de la música clásica, dominado por los blancos.

A su historia, Cromos dedicó varios artículos, en dos de ellos (Morales,1982; Ponsford, 1998) fue la misma Teresa quien contó su vida. En ambos casos, el relato de la artista se ve precedido por una introducción en la cual se explica quién es Teresa Gómez. El primero, de 1982, la presentó como una mujer crecida en una sociedad racista, que "por azar" había vivido en un palacio y que allá, "como el más serio juego infantil" había aprendido a tocar el piano. Sería, además, una "pésima" estudiante y una excelente bailarina de salsa (Morales, 1982). El segundo texto, de 1998, utilizó argumentos parecidos, presentándola como una mujer "vehemente", "loca", "desbocada", "incandescente", que se había entregado "al baile, a la noche, a los amores oscuros, con la frenética voracidad pagana de quien (...) tiene todo que perder pero lo arriesga en un giro de dados porque así lo dicta la naturaleza”. Una mujer, además, que no era consciente de sí misma y de su talento:

Ella sospecha que la verdadera conciencia de lo trágico está precisamente en su carácter inevitable. Ella sospecha que no cambiaría las consecuencias de cada uno de los acongojados amores de su vida por la estricta disciplina de intérprete, que quizás la hubiera llevado más lejos. Ella sospecha que no conoce la mesura (...). Pero si ella supiera, si ella tan solo sospechara de verdad quién es no podría ser la que es. Porque tanto el desorden de su imaginación cuando se sienta a hablar, como la fuerza de su interpretación cuando se sienta al piano, tienen origen en su desbordamiento. (Ponsford, 1998)

Esta presentación se ve acompañada por un resumen de su vida de fábula, que comienza con su adopción por los porteros de Bellas Artes y sigue con su descubrimiento por una maestra de música que la había incluido entre sus alumnos y le habia conseguido una beca. Como en el caso de Laura Mosquera, también Teresa Gómez había vivido un cuento de hadas.

El azar es un tema común en los relatos sobre la vida de Laura Mosquera y de Teresa Gómez. Su éxito no depende de su trabajo sino de factores externos: un fotógrafo que la descubre en la calle en el primer caso; una maestra de Bellas Artes en el segundo. Ellas serían agentes pasivos en su vida y sobre todo, en su proceso de ascenso, que lograrian 
gracias a la intervención de un hombre (en el caso de Laura Mosquera) o de otra mujer, pero blanca, en el caso de Teresa Gómez.

Las dos historias difieren en otro aspecto que repite los estereotipos sobre las personas negras: la consciencia y la inconsciencia de lo que ellas son. El artículo sobre Laura Mosquera enfatizó en que, desde la adolescencia, Laura sería consciente de su hermosura (es decir, de su cuerpo), hecho que la llevaria a querer modelar. Por el contrario, Teresa Gómez no parecía ser una persona consciente de su talento, es decir, de su capacidad intelectiva, dejándose más bien guiar por su desbordamiento, es decir por su irracionalidad, totalmente dominada por un carácter inevitable que la llevaría a entregarse más al placer que a la disciplina. Hemos visto en el primer apartado que la racionalidad, la disciplina y el trabajo mental son calidades atribuidas a los hombres, a los blancos y a los sectores medio-altos de la sociedad.

Nacida pobre, negra y mujer, sin que le fueran atribuidas virtudes que contradijeran su origen de clase y racial (contrariamente al caso de Laura Mosquera), Teresa Gómez fue presentada como una artista dominada por su naturaleza, resumida en la articulación de su género, de su origen étnico racial y social. Parafraseando los fragmentos analizados, se podría decir que Teresa Gómez sería una pianista exitosa a pesar de sí misma, es decir, de todo lo que esta naturaleza implicaría.

El caso de Laura Mosquera es parcialmente diferente: aunque ella también sea exitosa por azar y en contraste con un destino que la condenaría a la marginación, se desempeña en un campo que, evidentemente, era considerado más cercano a lo que se esperaba de una persona de su origen, al implicar el uso del cuerpo y no del intelecto. Por el contrario, Gómez entra en un mundo blanco, pero en un campo en el cual sería fundamental el uso de una capacidad intelectual históricamente negada a las personas negras y a los pobres. De alli la mayor necesidad de los periodistas de explicar su presencia en ese mundo, el énfasis en los limites puestos por su naturaleza y, por consecuencia, en la ausencia del final feliz en sus cuentos de hadas.

En el caso de Laura Mosquera no se habló explícitamente de la ausencia de un final feliz, aunque los autores subrayaron su soledad: no tenía amistades aparte de la de un perro, ni un amor, es decir, un príncipe azul (Holguín y Pabón, 1974). La definición de Cenicienta sin final feliz fue usada en 1992, en un breve artículo dedicado a Teresa Gómez. Teresa lo sería en cuanto "nació pobre y morirá sin castillo". Para ella, subrayó el autor, todo había sido difícil desde el comienzo: 
por haber sido abandonada por su madre biológica, por ser pianista "por azar", habiendo sido abandonada -según esta versión del relato"en las puertas del Palacio de Bellas Artes de Medellín", y por haber experimentado durante toda la vida el racismo de su familia adoptiva (la mamá la blanqueaba aplicándole ungüentos antes de los conciertos) y, más en general, de la sociedad colombiana (Díaz, 1992).

A diferencia de los relatos analizados anteriormente, en aquellos de finales del siglo XX aparece un tema nuevo: el racismo, para explicar la dificultad de inserción de las personas negras en la sociedad y sobre todo, en sus sectores acomodados. Las causas del reconocimiento de este fenómeno, precedentemente ignorado, remontan seguramente a la visibilidad que adquirió como consecuencia de las acciones de los movimientos sociales desarrollados desde la década de 1970 (Agudelo, 2005; Wagbou, Arocha, Salgado y Carabalí, 2012). De hecho, el racismo que apenas se encuentra mencionado en la historia de Laura Mosquera, cuya decisión de migrar a Venezuela sería originada por las dificultades que tenía una mujer negra de insertarse en el mundo del modelaje en Colombia (Holguín y Pabón, 1974), tuvo mucho espacio en los relatos sobre Teresa Gómez, así como en aquellos sobre otros personajes famosos como el cronista deportivo Edgar Perea y el actor Oscar Borda (Viveros et al., 2013).

Ya en 1982 el primer artículo que Cromos dedicó a la pianista la definió como una mujer crecida "con el estigma de ser negra" en una sociedad que, a pesar de que se dijera el contrario, era racista (Morales, 1982). El reconocimiento de la influencia del racismo en la vida de una persona negra representó sin duda una novedad importante. Sin embargo, a diferencia de lo que ocurrió en la prensa negra ${ }^{11}$, no fue analizado en sus raíces históricas y estructurales. Más bien, fue presentado como una prueba ulterior de la inevitabilidad que marcaria la vida de una persona negra: así como le sería dificil escapar a su naturaleza, de la misma manera no podría escapar al racismo, que limitaba aún más su posibilidad de inserción en la sociedad, frustrando así la posibilidad de conquistar un final feliz.

\footnotetext{
11 Me refiero particularmente a las publicaciones realizadas por organizaciones como el Centro para la Investigación de la Cultura Negra, las revistas Negritud (1977-1978) y Presencia Negra (19791984), que a lo largo de su existencia enfatizaron los orígenes históricos del racismo colombiano, proponiendo medidas para una solución del problema (Viveros et al., 2013).
} 


\section{A manera de conclusión}

Las historias analizadas en este artículo tienen en común la representación del ascenso social de personas negras como un fenómeno anómalo, que contrastaba con los imaginarios construidos históricamente sobre esta población, ubicada en la base de la jerarquía racial de la Nación en cuanto negra y en la jerarquía de clases en cuanto mayoritariamente pobre. Ambos factores determinarian su supuesta incompatibilidad con los valores de la clase media y de las elites, racialmente identificadas como blancas, que se caracterizarian por su racionalidad y control (del capital económico y del cuerpo, a través del dominio de la sexualidad que ésta se atribuía). La población negra, imaginada como una población irracional, descontrolada en la administración de su patrimonio así como en el ejercicio de la sexualidad, priva de cultura, tendiente al despilfarro y al alcohol, estaría imposibilitada para insertarse en un lugar social diferente a los sectores populares a los cuales su mayoría pertenecía. De allí las diferentes maneras de representar el ascenso social de algunas personas de ese grupo, caracterizadas también por las peculiaridades de la época en que fueron producidos dichos relatos.

La historia de Antonio José Camacho refleja los ideales y las contradicciones de la ideología del mestizaje. Su triunfo fue explicado en la medida en que el juez caleño demostraría su adhesión a esa ideología, dejando de lado cualquier reivindicación como negro y adhiriendo a los valores dominantes, tanto a través de la educación y un trabajo prestigioso como casándose con una mujer blanca. Es decir, tal como lo predicaba la ideología del mestizaje, tenía que acercarse a los sectores dominantes adquiriendo lo que el periodista Luis Enrique Osorio definió como una máscara de blancura. Eso no implicaba la cancelación de su origen étnico-racial (de hecho, como observé, siguió siendo definido el negro Camacho) pero sí la atenuación de las características atribuidas a los hombres de ese grupo. De hecho, al triunfo de Camacho corresponde la derrota de Chivas que no logra ascender socialmente ni acceder a una unión interracial con una persona del grupo considerado como superior y permanece entonces en una condición de marginación y pobreza a la cual lo condenaria su "destino [de] negro".

Los relatos acerca de la trayectoria ascendente de algunos deportistas, ejemplificados en la definición de Kid Pambelé como desplazado social, muestran la cuestión bajo otra perspectiva. La imagen del desplazado social hacía referencia a la supuesta división, que experimentarian quienes vivian esos procesos, entre el lugar social de origen 
y su nueva condición. El lugar social de origen se expresaria en una representación de clase y de raza que consideraba a un hombre nacido pobre y negro, incapaz de adquirir los valores de las clases (y del grupo racial) dominante: capacidad de administrar su patrimonio, de ser un buen marido y un buen padre, de adquirir buenos modales. Se podria generalizar diciendo que se trataba de personas pobres y negras que entraban en los espacios propios de las personas acomodadas y de los blancos sin liberarse totalmente de sus estigmas de origen. De allí la insistencia en el proceso descendente que seguiría a la época de riqueza, lo que haría evidente la imposibilidad de escapar a una condición que era considerada como natural.

Las historias de Laura Mosquera y de Teresa Gómez añaden nuevos elementos a los esquemas anteriores. Por un lado, la pasividad atribuida a las dos en su proceso ascendente, ocurrido por azar y por la intervención determinante de otras personas, pertenecientes -por género o por raza- a los grupos dominantes. Por el otro, la limitación de este ascenso debido al estigma representado por su color de piel, que se expresaria en el distanciamiento de Mosquera del estereotipo de las mujeres chocoanas, lo que da lugar a su éxito y en la persistencia de su naturaleza irracional y descontrolada en Teresa Gómez, que le obstaculizaria la posibilidad de llegar más lejos.

A diferencia de las historias de los deportistas, las de Mosquera y Gómez no concluyen con la pérdida de la posición conquistada. Sin embargo, retomando la terminología de cuentos de hadas que fue utilizada para relatar sus trayectorias, no concluyen tampoco con un final feliz. Particularmente en el caso de Teresa Gómez, los prejuicios se ven acompañados por el reconocimiento de la influencia del racismo en su vida que, visto como fenómeno inevitable, limitaría su posibilidad de alcanzar una inserción total en la sociedad, lo que la convierte en un personaje marginal.

Los retratos analizados permiten plantear una diferencia entre las representaciones del ascenso de hombres y mujeres negras. Parcialmente, ellos retoman los estereotipos de género dominantes. Ejemplo de esto es la ya mencionada pasividad atribuida a Laura Mosquera y a Teresa Gómez, y la dependencia de su ascenso de la intervención de personas pertenecientes a los sectores dominantes. A ella se contrapone el rol activo que Camacho, Pambelé, e incluso Chivas, ejercen en ese mismo proceso. Sin embargo, ni las unas ni los otros son considerados hombres y mujeres en el sentido tradicional que se atribuye a esos términos. En los casos de Chivas, Kid Pambelé, Laura Mosquera 
y Teresa Gómez, la articulación raza-género puede ayudar a explicar los limites de sus proyectos de ascenso y/o el fracaso con que se concluyen y que hacen de ellos hombres anómalos y mujeres anómalas.

El hecho de perder Kid Pambelé su patrimonio o, en el caso de Chivas, de terminar siendo un habitante de la calle, pueden ser vistos como un fracaso en un ámbito considerado típicamente masculino (añadiendo a este término, como propone López Pedreros, un significado de clase). Por su parte, la insistencia en la soledad emocional o en la promiscuidad aleja a Laura Mosquera y a Teresa Gómez de la femineidad tradicional. Aunque exitosas, no conquistan un lugar doméstico que haga de ellas verdaderas mujeres. Como hemos visto, serian las características consideradas ínsitas al hecho de ser mujeres negras las que les impedirian adherir a los estereotipos sobre la femineidad. Por adherir -según quien relató su historia- totalmente a los patrones dominantes. Camacho representa una excepción, sin embargo, las dinámicas que permiten a su historia, según el artículo de Osorio, tener un final feliz, es decir, un acercamiento exitoso a la blancura, paradójicamente confirman la dificultad de inserción que históricamente han tenido los grupos marginados en la sociedad.

\section{Referencias}

Abello, L. E. (1942, 9 de mayo). Chivas, el pobre negro. Cromos, (1324), 10.

Agudelo, C. (2005). Retos del multiculturalismo en Colombia. Politica y poblaciones negras. Medellin: La Carreta Social.

Araújo, F. (1991, 4 de noviembre). Hasta a Dios le fallé. Cromos, (3849), 58.

Azevedo, T. (1953/1996). As elites de cor numa cidade brasileira. Um estudo de ascensão social \& clases sociais e grupos de presígio. Salvador: Empresa Gráfica da Bahía.

Baldovi, J. M. (1994, 19 de septiembre). El mundo de Harold Gray. Cromos, (3999), 50.

Blommaert, J. y Bulcaen, C. (2000). Critical Discourse Analysis. Annual Review of Anthropology, 29, 447-466.

Bustamante, W. A. (2008). Homofobia y agresiones verbales. La sanción por transgredir la masculinidad hegemónica. Colombia 1936-1980. Medellín: Todográficas.

Castaño, O. (1975, 3 de diciembre). Pambelé: campeón mundial de gran corazón. Cromos, (3020), 112. 
Crenshaw, K. (1991). Mapping the Margins: Intersectionality, Identity Politics, and Violence against Women of Color. Stanford Law Review, 43 (6), 1241-1299.

Cromos. (1976, 26 de mayo). A los varones hay que respetarlos y yo soy un señor varón. Cromos, (3045), 14.

Díaz, H. (1992, 14 de septiembre). Teresa Gómez y Emilio Sanmiguel. Pareja profesional. Cromos, (3894), 94.

Fanon, F. (1952/2009). Pieles negras, máscaras blancas. Madrid: Akal.

Figueiredo, A. (1990). Novas elites de cor: estudo sobre os profissionais liberais negros de Salvador. São Paulo: Annablume, UCAM y CEAA.

Friedemann, N. (1983). Negros en Colombia: invisibilidad y presencia. En Zapata Olivella. El negro en la historia de Colombia: fuentes escritas y orales (pp. 69-91). Bogotá: Fundación Colombiana de Investigaciones Folclóricas.

Friedemann, N. (1992, junio). Negros en Colombia: identidad e invisibilidad. América negra, (3), pp. 25-35.

Gil, F. (2010). Vivir en un mundo de blancos. Experiencias, reflexiones y representaciones de 'raza' y clase de personas negras de sectores medios en Bogotá D.C.. Tesis de Maestría en Antropología no publicada. Universidad Nacional de Colombia. Bogotá, Colombia..

González, J. H. (1994, 30 de mayo). Kid Antonio. Cromos, (3983), 58-59.

Gossaín, J. (1972, 6 de noviembre). Mi 'vieja' no venderá más papayas en Cartagena. Cromos, (2859), 6.

Gossaín, J. (1973, 26 de febrero). Con Pambelé en Puerto Rico. Cromos, (2875), 4.

Gossain, J. (1973, 26 de marzo). ¡Chau Nicolino! Cromos, (2879), 78.

Gossaín, J. (1974, 11 de marzo). Con un sicólogo seguimos al Pambelé que Colombia no conoce. Cromos, (2929), 4.

Hering, M. (2011). Color, pureza, raza: la calidad de los sujetos coloniales. En H. Bonilla (Ed.). La cuestión colonial (pp. 451-469). Bogotá: Norma.

Holguín, H. (1973, 7 de mayo). La familia Pambelé. Cromos, (2885), 20-21.

Holguín, H. y Pabón, M. (1974, 6 de mayo). Laura Mosquera. La 'Cenicienta' negra que se fugó del Chocó a triunfar en Venezuela. Cromos, (2937), 34.38.

López Pedreros, R. (2009). Ser de clase media no es algo que pasa de la noche a la mañana. Empleados, mujeres de oficina y la construcción de las identidades de clase media en Bogotá, 1930-1950. En S. Visacovsky y E. Garguin (Eds.). Moralidades, economías e identidades de clase media. Estudios históricos y etnográficos (pp. 164-194). Buenos Aires: Antropofagia.

McCall, L. (2005). The Complexity of Intersectionality. Signs, 30 (3), 1771-1800.

Morales, A. (1982, 3 de agosto). La negra está tocando el piano. Cromos, (3368), 102-107. 
Moutinho, L. (2004). Razã, "cor" e desejo: uma análise comparativa sobre relacionamentos afetivo-sexuais "inter-raciais" no Brasil e África do Sul. Sao Paulo: Editora de la Unesp.

Osorio, L. E. (1943, 30 de octubre). El negro Camacho, o el triunfo de un estudiante pobre. El Sábado, 6 y 14.

Pisano, P. (2009, septiembre). Sociabilidad gay y lésbica en Bogotá en los años setenta y ochenta. Ponencia presentada en la VIII Reunión de Antropología del Mercosur (RAM). Buenos Aires, Argentina, septiembre de 2009.

Pisano, P. (2012a). Liderazgo politico 'negro' en Colombia, 1943-1964. Bogotá: Universidad Nacional de Colombia, Facultad de Ciencias Humanas.

Pisano, P. (2012b). Un 'rincón de África' en Colombia. Representaciones sobre el Palenque de San Basilio a mediados del siglo XX. Ponencia presentada en el XVI Congreso de Historia. Neiva, Huila, octubre de 2012.

Ponsford, M. (1998, 10 de agosto). Siete corazones tengo, pero el mío no lo encuentro. Cromos, (4201), 36-41.

Ricci, M. (1977, 30 de marzo). Odio a los periodistas colombianos. Ellos quieren perjudicarme. Cromos, (3089), 22.

Rojas, C. (2001). Civilización y violencia. La búsqueda de la identidad en la Colombia del siglo XIX. Bogotá: Editorial Norma.

Samper, D. (2000, 22 de mayo). El más grande impostor. Cromos (4294), 22-30.

Urrea, F. (2011). La conformación paulatina de las clases medias negras en Cali y Bogotá a lo largo del siglo XX y la primera mitad del siglo XXI. Revista de Estudios Sociales, 39, 24-41.

Van Dijk, T. A. (2010). Racismo y discurso. En O. Hoffman y O. Quintero (Eds.). Estudiar el racismo: textos y herramientas (pp. 102-128). México: Afrodesc, cuaderno de trabajo n. 8.

Viveros, M. (2007). Discriminación racial, intervención social y subjetividad. Reflexiones a partir de un estudio de caso en Bogotá. Revista de Estudios Sociales, (27), 106-121.

Viveros, M. (2008). La sexualización de la raza y la racialización de la sexualidad en el contexto latinoamericano actual. En G. Careaga. Memorias del primer encuentro latinoamericano y del Caribe. La sexualidad frente a la sociedad (pp. 168-198). México D. F., 2008.

Viveros et al. (2013) Informe final del proyecto "Escapando a la desdicha genealógica. El surgimiento y participación de las clases medias 'negras' en la vida nacional colombiana". Universidad Nacional de Colombia, Colciencias.

Viveros, M. y Gil, F. (2010). Género y generación en las experiencias de ascenso social de personas negras en Bogotá. Maguaré, 19, 99-130.

Wade, P. (1997). Gente negra, Nación mestiza. Dinámicas de las relaciones raciales en Colombia. Bogotá: Siglo del Hombre, Ediciones Uniandes. 
Wade, P. (2003). Repensando el mestizaje. Revista Colombiana de Antropología, 39, 273-296.

Wagbou, M., Arocha, J., Salgado, A. J. y Carabalí, J. A. (2012). Movimiento social afrocolombiano, negro, raizal y palenquero: el largo camino hacia la construcción de espacios comunes y alianzas estratégicas para la incidencia política en Colombia. Bogotá: Universidad Nacional de Colombia.

Zapata, M. (1990). ¡Levántate mulato! Por mi raza hablará el espiritu. Bogotá: Rei Andes. 